\title{
Impact of personnel creativity on achieving strategic agility: The mediating role of knowledge sharing
}

\author{
Amineh A. Khaddam ${ }^{\text {a* }}$
}

${ }^{a}$ Amman Arab University, Jordan

\begin{tabular}{ll}
\hline C H R O N I C L E & A B S T R A C T \\
\cline { 1 - 2 } $\begin{array}{l}\text { Article history: } \\
\text { Received: February 2, 2020 } \\
\text { Received in revised format: }\end{array}$ & $\begin{array}{l}\text { This study aims to examine the impact of the Personnel Creativity (PC) on Strategic Agility (SA) } \\
\text { on the Sama Jordan for Food and Industrial Investments using Knowledge Sharing (KS) as a me- } \\
\text { diating variable. The study also examines the interrelationships between the constructs influencing }\end{array}$ \\
$\begin{array}{l}\text { Accepted: March 7, 2020 } \\
\text { Available online: }\end{array}$ & $\begin{array}{l}\text { SA. The study sample includes all the employees of the company of Sama Jordan for Food and } \\
\text { Industrial Investments. In order to gather the required data, the study designs and distributes some }\end{array}$ \\
$\begin{array}{ll}\text { March 7, 2020 } & \text { questionnaire among different employees. Qualitative data is mainly collected to answer the re- } \\
\text { Keywords: } & \text { search questions. Additionally, 76 valid surveys are used for data analysis and testing of hypotheses } \\
\text { is performed by employing AMOS program. The results indicate that KM was the mediating vari- } \\
\text { Strategic Agility }(S A) \\
\text { Knowledge Sharing }(K S)\end{array}$ & $\begin{array}{l}\text { able on the relation between PC and SA. Overall, the proposed model helps the employees who } \\
\text { work in the organization to increase our understanding on how these factors interact in order to } \\
\text { create value to customers and develop future strategies to improve SA. }\end{array}$
\end{tabular}

\section{Introduction}

Creativity has become a topic of ever-increasing with globally competitive marketplace, and the ability to be creative - individually and in groups - has been assumed increasing an effective management which requires capability for both personal creativity and the ability to enhance creativity in the organizations. According to Kumkale (2016), the concept of strategic agility (SA) requires permanently the different environments for the organization, assembly and employing knowledge quickly, and replying to marketplace modifications, rapidly. Therefore, the need to understand the significance of creativity and the creative process within an organizational context is ultimately precious asset.

Moreover, Luo et al. (2015) noted that the idea of creativity in the use of Information Technology (IT) is significant to the performance and continuing attainment of marketplace; and can be noticeable feature for organizational novelty and improve the capabilities related the operation. Even more, to identify the importance of creativity and creativity process in contemporary organizations requires exploration of its foundation related to strategy of organizations and how to create the knowledge and to develop new capabilities, products, processes, and services.

Furthermore, Kale et al. (2019) explain that the growing recent amount of literature review has motivated on the feature of SA, scant investigation occurs exploring the connection between SA and human resource management. Consequently, the business organizations face challenges that may affect its market share hence their treasury is its human resource which require organizations to use new techniques and methods to develop their individual capability to be creative within the context of group work and the broader organization as the creativity is a skill that can be developed. Also, Lu and Ramamurthy (2011) 
state that the structural of agility in organization covers the controllability and suggest that agility in organization includes two different ideas namely: market place exploiting agility and functioning alteration agility.

Apart from that, most organizations are innately looking for solving their problems effectively and efficiently in today's fast altering and progressively international corporate situation and that requires a creative minded employee. The speed of changes in current environment along with hyper competitiveness requires internal readiness to react (response) to the change and nevertheless finding new methods of running businesses by competing sustainably, this is called Agility. First and foremost, a rich appreciative of the source and environment of creativity and strategic thinking of an individual should be addressed to reach SA (Tsai, 2012). Moreover, a variety of theorists stipulated that strategic success (and to have a greater chances of success) requires an exploration of the strategic thinking which in turn requires creativity and innovation.

The completed idea clarifies for all parties to create all integrated collaboration events undertaken interdependent in order to improve new process to improve the innovation procedure (Mahr et al., 2014) by implementing the formation, conversation and relocation all knowledge, creativity and information resources. Additionally, Messeni et al. (2018) noted that the actual relocation and gaining of information after summarizing to backing co-creation is vital to create novelty as an effective procedure to permit the assessment policy from the grouping of current familiarity information resources. Consequently, in combining with strategic thinking, the manager thoughtfully deliberates how to make value to customers and develop upcoming policies through SA. Furthermore, the concept of SA depends on the parts of leadership, organizational systems and change agents to categorize how organizations ensure that novel concepts are accepted and how to examine the concept of the intelligent organization and the connected concepts of KS within the process of knowledge management(KM).

Absolutely, to continue in the chaotic situation needs to be in persistent exploration for new business chances and thus residing on top of the rivalry also means being capable of creating fast processes to influence the organization's large objective for future. However, this study comes to examine the association and the influence of PC on achieving SA by mediating the role of KS in Jordan business organizations.

The next part drives the current literature review related to topics, part three presents research model and hypothesis development. In section four we present a summary for research method applied for the experimental section of the paper. Section five presents and discusses the data analysis and experiential results and final part presents the conclusion.

\section{Literature Review}

This part consists three part of the background to the literature review. Literature such as: Definition of Creativity and PC, $\mathrm{SA}$, and $\mathrm{KS}$ is also discussed.

\subsection{Creativity and Personnel Creativity (PC)}

Creativity as a mental process that leads to generate a novel and new ideas that others value is the key aspects of innovation process and address competitive advantage. Psychologists provides the most developed perspectives on the source of creativity and place more attention on it. There is an indication to recommend that creativeness as a characteristic of innovative attainment (Ludvig et al., 2016), is a significant determination for the innovative procedure, assistances the detection of novel organizational chances, and highlights the important part that entrepreneurship and novelty show an asset of commercial development in business.

The creativity needs to evolve novel concepts and perceptions that are operative in determining circumstances at hand. Additionally, the concept of creativity is considerable around detecting the business situation and discovery problems as it is about problem explaining. As a consequence, creativity is a skill that can be developed and can be used to resolve problems encounter employees fastest than ever. Therefore, creativity is deeply rooted in thinking where strategic thinking and creativity is originated in theoretical studies as two sides of the same coin (Idris \& Al-Rubaie, 2013; Irtaimeh et el., 2016). Furthermore, the concept of strategic thinking refers to create an innovative and complete combination of important elements affecting a business and its situation to attain strategic success.

Çekmecelioğlu and Günsel (2013) stated that creative employees are more likely to determine customers' unidentified wants and effectively address the problems with solving them creatively. According to Amabile (1996) there are three major factors of individual creativity in organization: 1) expertise which refers to information processed, skills, and capabilities to create offerings in their field. 2) thinking innovation services which includes thinking practices as well as behavior personalities to effect original thinking skills. and 3) intrinsic task incentive which includes working on an interesting, exciting, satisfying, and personally challenging that turn innovative potentials into real innovative concepts.

As a consequence, individual creativity is a critical in order to enhance creativity in business organizations. This notion requires analyze the dynamic interactions between collective individuals as a team to influence individuals' creativity. Thus, creativity is defined as a difficult element that can be recognized in people, products, processes, and the situation. Creativity 
in literatures refers to the novel and valuable thing. Therefore, many researchers and practitioners who studied creativity in organizations have focused only on products, people, processes, situation, and new ideas, where these are a ground for innovation (Munz-Doyague \& Nieto, 2012).

\subsection{Strategic Agility (SA)}

The fast altering business requirement is based on competitors from external environment and increasing complete interdependencies which creates organization progressively difficult executed on business to be tactically innovative (Hamel, 2007; Santala, 2009; Vokurka \& Fliedner, 1998). Fig. 1 epitomizes the replies to alteration from slow to fast related on speed of change, and from simple to complex related to nature of change (Doz \& Kosonen, 2008).

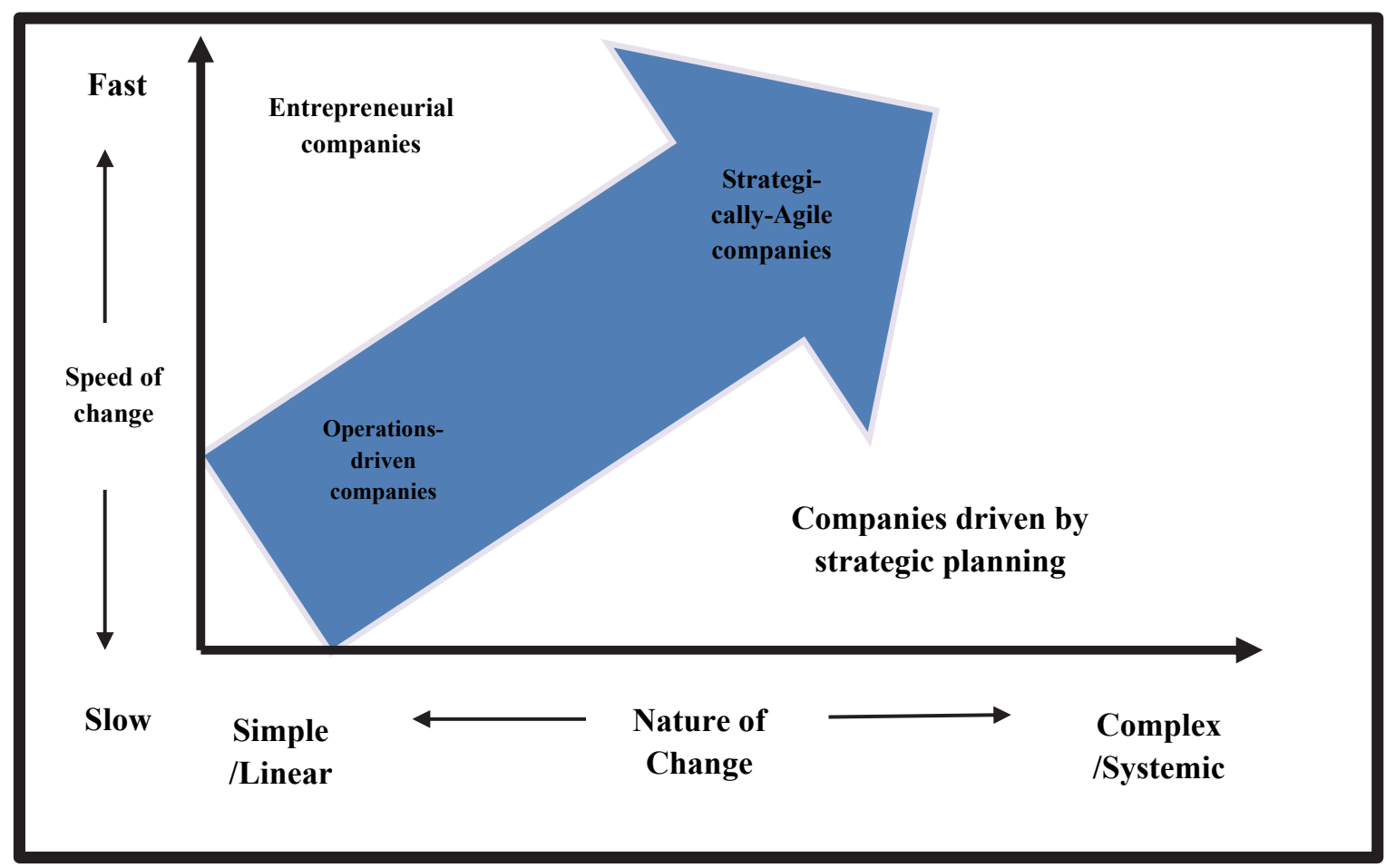

Fig. 1. Responses to Change (Doz and Kosonen, 2008)

Gunasekaran (1999) defines the concept of Agility as competence of ongoing and growing in good circumstances of survival and changeable modification by responding rapidly and professionally to any altering for marketplace, determined by practice planned for goods and service. Additionally, several of philosophers and experts describe tactical agility chunkily; Doz and Kosonen (2008) note that the concept of SA denotes to learn to create talented and rebuild the plan within the organization without dropping new chances.

Brannen and Doz (2012) define that the SA is a capability to grow strategic changes and create well-grounded, considerate decision making as soon as possible. Additionally, this definition proposes that SA focuses in making the strategy more applicable rather than focusing on it as performance competence. In other words, SA is the capability to satisfactorily adopt in suitable time in strategic way of business compared with altering setting, which is called sensitivity to the situation (Ofoegbu \& Akanbi, 2012). Furthermore, for plan practices related to strategic agility in organizations we need to achieve the unexpected variations and threats faced by these organizations.

Doz and Kosonen (2008) define that SA in business is constant practices and capability to interpret any changes related to organizational environment and distribution of all resources as soon as possible based on requirement to achieve the organization objective by considering three important dimensions called strategic feeling, source flexibility, and cooperative guarantee (Doz \& Kosonen, 2008).

Furthermore, Sajdak (2015) clarifies that the idea of strategic agility considers as method in organization in order to develop the new way and direction in organization to make the innovative practices for creating value to organization. Additionally, business which through creativity and novelty can generate market chances characterize the second level of agility and finding 
market chances through discovering new requirements is somehow diverse than replying to chances for justifying the requirements which appear on the marketplace and it needs from staffs with complete knowledge, innovation practices and creativity (Sajdak, 2015). Doz and Kosonen (2008) note that the SA is made up of three vital features called: strategic sensitivity, resource fluidity, and leadership unity. Other researchers identified organizational agility as concept (Tallon \& Pinsonneault, 2011). While others identified enterprise agility as concept (Overby et al., 2006). Therefore, this study considers the three dimensions of SA as follow: Strategic Sensitivity, Resource Fluidity, and Collective Commitment.

\subsection{Knowledge Sharing $(K S)$}

$\mathrm{KM}$ is a relatively new discipline that attracted attention of academic practitioners and researchers, and yet, KM is progressively accepted as a strategic factor in gaining competitive advantage (Emami Saleh et al., 2010; Obeidat, 2019). Despite the vast and range of KM literatures, still there is no consensus between researchers of KM definition yet, but some of them can define it as a process in which organizations can formulate new ways to identify and storage knowledge assets inside organization to be used for the strategic goal. In other words, KM is the process of making knowledge available and usable for more than employee, and thus, sharing knowledge with others within an organization. However, many researchers agreed on definition of KM as a process by which knowledge is generated, stored, collected, shared, transmitted, applied, exploited, and measured to matched with organization's needs (Egbu \& Botterill, 2003; Obeidat \& Otibi, 2015). In respect of all organizations, knowledge generating is as important as knowledge sharing, and the empowerment of staffs to make and KS is the task of organization. To encourage employees to do so, the top management must implement reward and punishment schemes and motivating employees to share knowledge between them is mandatory (Scarbrough et al., 1999; Saffar \& Obeidat 2020). Therefore, individuals with a high knowledge will be able to be more creative, and thus possessing more competencies to provide improved products and services as well as diagnosing the customer' needs, this could create a new competence to employees to be more agile than other competitor employees. Also, Chiang et al. (2011) confirmed that the concept of knowledge leads to strengthening individuals' essential capabilities and increased the needed assets for organizations to innovate and compete, the most powerful is knowledge sharing. The competitive advantage of many organizations is ultimately defined by the magnitude of knowledge sharing, which must be encouraged and nurtured to enhance individual creativity and agility (Uriarte \& Filemon, 2008).

\section{Research Model and Hypothesis}

Based on the above literature review, the proposed model is initially developed shown in Fig. 2. The independent variable is called PC, dependent variable is called SA, and Mediating variable is called KS.

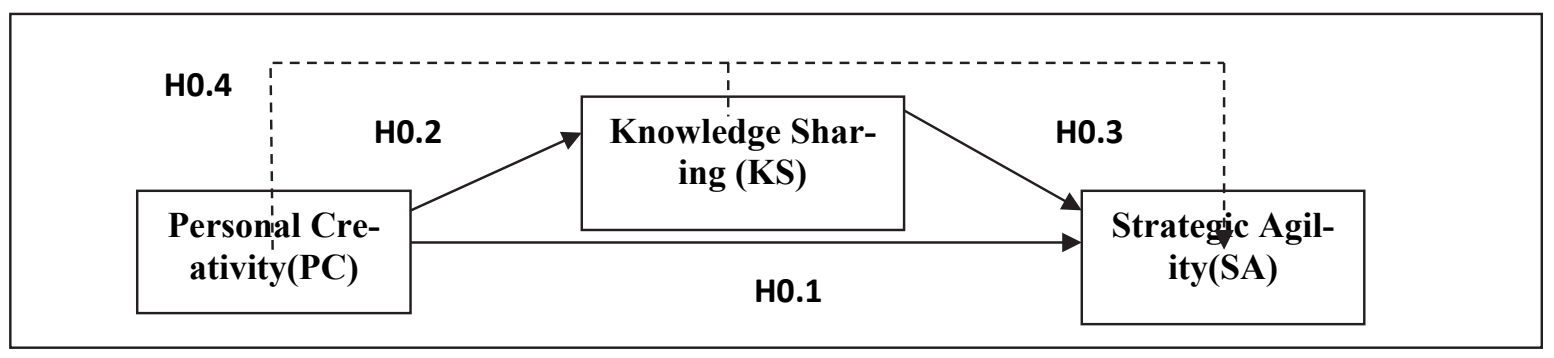

Fig. 2. Research Model

Based on the above model, the researcher has developed the following four hypotheses that represent the direct and indirect relationship between variables:

$\mathrm{H}_{01}$ : Personal creativity (PC) influences strategic agility (SA).

$\mathrm{H}_{02}$ : Personal creativity (PC) influences knowledge sharing (KS).

$\mathrm{H}_{03}$ : Knowledge sharing (KS) influences strategic agility (SA).

$\mathrm{H}_{04}$ : Knowledge sharing (KS) positively mediates the relationship between PC and SA.

\section{Research Methodology}

\subsection{Data collection}

The study survey was considered by means of accepting readily established variables from the literature review. The PC is considered as independent variable. Additionally, the items used to measure mediating variables called KS (including knowledge donating and knowledge collecting) were adopted from Obeidat et al. (2017), and items used to measure dependent variables called SA (including Strategic Sensitivity, and Resource Fluidity). 
The survey was disseminated on to answer statements on the 5-point Likert Scale where 5 specified strongly agree and 1 indicated strongly disagree. The survey was primarily prepared in Arabic and then converted into English language. Both English and Arabic versions were revised by 5 professors in Business Administration.

\subsection{Population and Sample}

The population for the study contained of Sama Jordan Food and Industry of Jordan. A random sampling was selected, consequently, a total of 98 questionnaires were disseminated. 82 questionnaires were returned. 6 questionnaires were distinct as useless and were omitted from subsequent examination. The last number of practical questionnaires was 76.

\section{Data analysis and result}

\subsection{Descriptive Analysis}

The initial stage in examining the data collected was to describe the descriptive measurements of the responses gained from the data. The descriptive measurements for items are illustrated in Table 1. The mean, standard deviation (SD), Min, Max, Correlation coefficients to investigate the discriminant validity among of each measurement item were calculated related to questionnaire constructs.

Table 1

Descriptive statistics

\begin{tabular}{|c|c|c|c|c|c|c|c|}
\hline \multirow[t]{2}{*}{ Constructs } & \multirow[b]{2}{*}{ Mean } & \multirow[b]{2}{*}{ SD } & \multirow[b]{2}{*}{ Min } & \multirow[b]{2}{*}{ Max } & \multicolumn{3}{|c|}{\begin{tabular}{|c|} 
Correlation coefficient \\
\end{tabular}} \\
\hline & & & & & $\begin{array}{c}\text { Personal Crea- } \\
\text { tivity } \\
\text { (PC) }\end{array}$ & $\begin{array}{l}\text { Strategic } \\
\text { Agility } \\
\text { (SA) }\end{array}$ & $\begin{array}{c}\text { Knowledge Shar- } \\
\text { ing } \\
(\mathrm{KS})\end{array}$ \\
\hline Personal Creativity(PC) & 3.455 & 0.739 & 1.750 & 5.000 & 1.000 & & \\
\hline Strategic Agility(SA) & 3.660 & 0.626 & 1.333 & 4.583 & $0.719^{* *}$ & 1.000 & \\
\hline Knowledge Sharing(KS) & 3.645 & 0.609 & 1.219 & 4.625 & $0.619 * *$ & $0.703 * *$ & 1.000 \\
\hline
\end{tabular}

Table 1 indicates that the mean values ranged from lowest mean was for $(\mathrm{PC})=3.455$ to the highest mean for $(\mathrm{SA})=3.660$ on the 5-point scale and representative that all the measure items were usually disseminated and replicated the level of approval on the satisfied of questions made for individual respondents. Additionally, the standard deviation (SD) of the responses reflects the low degree of dispersion, the SD ranged from 0.609 for (KS) to 0.739 for (PC) on the 5-point scale and indicating that all the scale items were typically disseminated. Moreover, the Min values ranged from lowest mean was for $(\mathrm{KS})=1.219$ to highest mean for $(\mathrm{PC})=1.750$ on the 5 -point scale. Also, the Max values ranged from lowest mean was for $(\mathrm{SA})=4.583$ to highest mean for $(\mathrm{PC})=5.000$ on the 5-point scale, and indicating that all the scale items response were normally distributed. This shows the consistency in the responses response that supports the assurance of the importance of (KS), (PC), and (SA). Also, the correlation coefficient values indicated that there was a significant relationship among model variables. In addition, the values of correlation coefficients among independent variables were all less the (0.719), which indicate that data free of multicollinearity problem. The correlation coefficient values indicated that there was a significant relationship among model variables.

\subsection{Measurement Model Evaluation}

\subsubsection{Validity Test}

To test the suitability of the research constructs, the face and content validity were used. This involved by investigate the questionnaire by readingfrom5specialists in field of Business Administration exist in4 different universities in Jordan in order to ensure the content validity of the questionnaire. In addition, the author makes a meeting with five workers employed in different Sama Jordan to assess the suitability and significance of the survey constructs in order to ensure the face validity related to questionnaire. Furthermore, the author reviewing different research paper related to wholly constructs in proposed model in order to write the all questions in questionnaire. Additionally, the author evaluated the Exploratory Factor Analysis (EFA) test to ensure that wholly constructs loaded into one factor with minimum level that determine by greater than 0.40 . and if any item does meet this criterion need to be removed (Sekaran, 2006). Table (2)displaysthe EFA results for all the variable scales.

Table 2

Factor Load of Research Variables

\begin{tabular}{llll}
\hline Variable & Factor Load & Variable & Factor Load \\
\hline Personal Creativity & 0.936 & Collective Commitment & 0.842 \\
Strategic Agility & 0.989 & Knowledge Sharing & 0.962 \\
Strategic Sensitivity & 0.856 & Knowledge Donating & 0.976 \\
Resource Fluidity & 0.865 & Knowledge Collecting & 0.838 \\
\hline
\end{tabular}




\subsubsection{Reliability Test}

The researcher has used Cronbach Alpha (CA) Coefficient Test. According to Table 3, Internal Consistency estimate CA values of the study instrument items range from (0.814 - 0.907), and that Alpha value for all items is (0.74), and thus all values are higher than (0.60). This is an indicator of consistency between the items of the instrument and the reliability of the study instrument, and thus it can be used for doing statistical analysis. The scale outcome is statistically accepted if the rate of CA is higher than (0.60) (Sekaran, 2006).

\section{Table 3}

Cronbach's $\alpha$-Coefficient

\begin{tabular}{lccc}
\hline Variable & Cronbach's $\boldsymbol{\alpha}$-coefficient & Variable & Cronbach's $\boldsymbol{\alpha}$-coefficient \\
\hline Personal Creativity & 0.845 & Collective Commitment & 0.880 \\
Strategic Agility & 0.907 & Knowledge Sharing & 0.814 \\
Strategic Sensitivity & 0.794 & Knowledge Donating & 0.783 \\
Resource Fluidity & 0.817 & Knowledge Collecting & 0.761 \\
\hline
\end{tabular}

The reliability of the study variables was confirmed by applying Cronbach's $\alpha$-coefficient. Everything the variables displayed a consistency of $\alpha \geq 0.70$ indicating a good reliability and internal consistency.

\subsubsection{Confirmatory factor analysis}

The analysis model was assessed by applying the confirmatory factor analysis (CFA) test in order to assess the model fit. Based on proposed model in Fig. 1, The outcomes of CFA are shown in Table 4.

Table 4

CFA results

\begin{tabular}{llcccc}
\hline \multicolumn{1}{c}{ Measure } & CMIN/DF & $\begin{array}{c}\text { Comparative } \\
\text { fit index } \\
\text { (CFI) }\end{array}$ & $\begin{array}{c}\text { goodness-of-fit } \\
\text { index (GFI) }\end{array}$ & $\begin{array}{c}\text { normed fit } \\
\text { index } \\
\text { (NFI) }\end{array}$ & $\begin{array}{c}\text { root mean square error of ap- } \\
\text { proximation } \\
\text { (RMSEA) }\end{array}$ \\
\hline Threshold value & $<5$ & $>0.90$ & $>0.90$ & $>0.90$ & $<0.10$ \\
Result for proposed model & 3.58 & 0.96 & 0.94 & 0.96 & 0.07 \\
\hline
\end{tabular}

The above table showed that CFA measures represent a good fit as CMIN/DF $=3.58$ of the scale items to be used in the main survey were lower the cut-off criteria of 5 (Byrne, 2001). Also, CFI $=0.96$, GFI $=0.94$, and NFI $=0.96$, as shown in Table 3, the CFI, GFI, and NFI of all the constructs were values close to .90 have been found to show good model fit (Byrne, 2001). Additionally, RMSEA $=0.07$ of the scale items to be used in the main survey were lower the cut-off criteria of 0.10 (Byrne, 2001).

\subsection{Hypotheses Testing}

The proposed model and the hypothesized associations amongst independent, dependent and mediation variables were tested through AMOS. See Fig. 3.

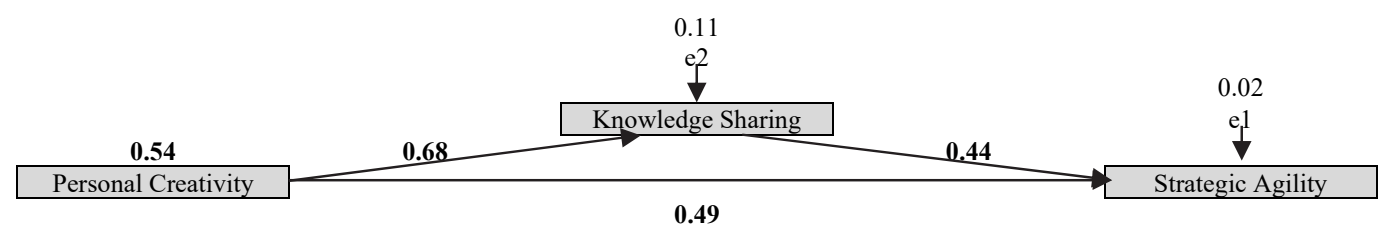

Fig. 3. The results estimated through AMOS

Based on Fig. 3, the author presents the results of the hypotheses testing. The standardized regression weights, standard Error (S.E) and the critical ratio (C.R) for $\mathrm{H}_{01}, \mathrm{H}_{02}$, and $\mathrm{H}_{03}$ are provided in Table 5 to decide accept or reject the hypotheses.

Table 5

The Direct and Indirect Estimates of Research Hypothesis

\begin{tabular}{cccccc}
\hline Relations & Estimate $(\beta)$ & S.E. & C.R. & p-value & Result \\
\hline $\mathrm{H}_{0.1}(\mathrm{PC}) \rightarrow(\mathrm{KS})$ & 0.685 & 0.046 & 14.886 & 0.000 & ${\text { Reject } \mathrm{H}_{0.1}}$ \\
$\mathrm{H}_{0.2}(\mathrm{KS}) \rightarrow(\mathrm{SA})$ & 0.442 & 0.045 & 9.923 & 0.000 & ${\text { Reject } \mathrm{H}_{0.2}}$ \\
$\mathrm{H}_{0.3}(\mathrm{PC}) \rightarrow(\mathrm{SA})$ & 0.495 & 0.037 & 13.474 & 0.000 & ${\text { Reject } \mathrm{H}_{0.3}}$ \\
\hline
\end{tabular}


Based on Table 5, Regression results indicated that the effect of $(\mathrm{PC})$ on $(\mathrm{KS})$ was significant $(\beta=0.685, \mathrm{p}=0.000)$, so there is a significant relation between independent and mediator variable. Also, the effect of (KS) on (SA) was significant $(\beta=$ $0.442, p=0.000)$, which means there is relation between mediator and dependent variable. Moreover, the effect of $(\mathrm{PC})$ on (SA) was significant $(\beta=0.495, \mathrm{p}=0.000)$, which indicates there is a significant effect of independent variable on dependent without a mediation effect.

Finally, the researcher uses the Regression results to ensure the KS was mediating the relationship between (PC) and (SA). The results are summarized in Table 6 .

Table 6

Direct, indirect and total effect model of mediation analysis

\begin{tabular}{|c|c|c|c|c|c|c|}
\hline \multirow[t]{2}{*}{ Relation } & \multicolumn{2}{|c|}{ Direct Effect } & \multicolumn{2}{|c|}{ Indirect Effect } & \multicolumn{2}{|c|}{ Total Effect } \\
\hline & $\mathrm{PC}$ & $\mathrm{KS}$ & $\mathrm{PC}$ & $\mathrm{KS}$ & $\mathrm{PC}$ & $\mathrm{KS}$ \\
\hline $\mathrm{KS}$ & $\begin{array}{l}0.685 \\
(0.010) \\
\text { Reject } \\
\mathbf{H}_{0.2}\end{array}$ & 0.000 & 0.000 & 0.000 & $\begin{array}{l}0.685 \\
(0.010) \\
\text { Reject } \\
\text { Ho.2 }\end{array}$ & 0.000 \\
\hline SA & $\begin{array}{l}0.495 \\
(0.010) \\
\text { Reject } \\
\mathbf{H}_{0.1} \\
\end{array}$ & $\begin{array}{l}0.442 \\
(0.010) \\
\text { Reject } \\
\text { Ho.3 }\end{array}$ & $\begin{array}{l}0.303 \\
(0.010) \\
\text { Reject } \\
\text { Ho.4 }\end{array}$ & 0.000 & $\begin{array}{l}0.797 \\
(0.010) \\
\text { Reject } \\
\text { Ho.1 }\end{array}$ & $\begin{array}{l}0.442 \\
(0.010) \\
\text { Reject } \\
\text { H. }_{0.3}\end{array}$ \\
\hline
\end{tabular}

The results of Table 6 show that (KS) partially mediated the relationship between (PC) and (SA). The mediation effect is significant as indirect effect $(\beta=0.303, p=0.010)$ of $(\mathrm{PC})$ on $(\mathrm{SA})$ is due to the mediator. Therefore, in the total effect we have $(\beta=0.797, p=0.010)$ for the effect of PC on SA.

\section{Conclusion}

The proposed model has shown an essential role in applying effective SA through using KS based on PC. Additionally, numerous frameworks have performed to increase the work of employees in the organization through the use and development of only PC factors. They also seem with unpredicted outcomes while many organizations consume the KS as mediating elements to determine all their difficulties and improve their work correctly to attain highly successful SA. The study has confirmed the positive effect of PC on achieving SA by employee and the role of KS is partially mediating off the relationship between PC and achieving SA in Sama Jordan for Food and Industrial Investments employees. The proposed model of the work convinced the Food and Industrial factory to rebuild its procedures for connected to strategy of organizations, considering to contain also KS inside the bundle of responsibilities to be restructured the strategy in order to enhance organization's business results. Furthermore, the suggested model is appropriate for assistant decision-making tasks in circumstances categorized by any of the Food and Industrial organizations.

\section{References}

Amabile, T.M., Conti, R., Coon, H., Lazenby, J. \& Herron, M. (1996). Assessing the work environment for creativity. Academy of Management Journal, 39(5), 1154-84.

Brannen, M.Y., \& Doz, Y.L. (2012). Corporate languages and strategic agility: trapped in your jargon or lost in translation? California Management Review, 54(3), 77-97.

Byrne, B. M. (2001). Structural equation modeling with AMOS, EQS, and LISREL: Comparative approaches to testing for the factorial validity of a measuring instrument. International Journal of Testing, 1(1), 55-86.

Chiang, H., Han, T., \& Chuang, J. (2011). The Relationship between high-commitment HRM and knowledge-sharing behavior and its mediators. International Journal of Manpower, 32, 604-622.

Doz, Y., \& Kosonen, M. (2008). Fast Strategy. Wharton School Publishing: Harlow.

Egbu, C., \& Botterill, K. (2003). Knowledge Management and Intellectual Capital: Benefits for Project Based Industries.

Emami Saleh, K., Ardalan, A., \& Valipour, F. (2010). Intellectual capital and knowledge management performance. International Journal of Arts and Commerce, 1(3), 1-12.

Gunasekaran, A. (1999). Agile manufacturing: A framework for research and development. International Journal Production Economics, 62(1-2), 87-105.

Hamel, G. (2007). The Future of Management. Harvard Business School Press: Boston.

Idris, W.S. \& AL-Rubaie, M., \& Taher, K. (2013). Examining the impact of strategic learning on strategic agility. Journal of Management and Strategy, 4(2), 70-77.

Irtaimeh, H. J., Obeidat, A. M., Abualloush, S. H., \& Khaddam, A. A. (2016). Impact of business intelligence on technical creativity: A case study on AlHekma Pharmaceutical Company. European Scientific Journal, 12(28), 502-519. 
Kale, E., Aknar, A., \&Başar, O. (2019). Absorptive capacity and firm performance: The mediating role of strategic agility. International Journal of Hospitality Management, 78, 276-283.

Kumkale, I. (2016). Organization's tool for creating competitive advantage: Strategic agility. Balkan and Near Eastern Journal of Social Sciences, 2(3), 118-124.

Lu, Y., \& Ramamurthy, K. (2011). Understanding the link between information technology capability and organizational agility: An empirical examination. MIS Quarterly 35(4), 931-954.

Ludvig, A., Tahvanainen, V., Dickson, A., Evard, C., Kurttila, M., Cosovic, M., \& Gerhard, W. (2016). The practice of entrepreneurship in the non-wood forest products sector: Support for innovation on private Forest land. Forest Policy and Economics, 66, 31-37.

Luo, Y., Zhang, C., Xu, Y., \& Ling, H. (2015) Creativity in IS usage and workgroup performance: The mediating role of ambidextrous usage. Computers in Human Behavior, 42, 110-119.

Mahr, D., Lievens, A., \& Blazevic, V. (2014). The value of customer co- created knowledge during the innovation process. Journal of Product Innovation Management, 31(3), 599-615.

Messeni, P.A., Ardito, L., \& Savino, T. (2018). Maturity of knowledge inputs and innovation value: The moderating effect of firm age and size. Journal of Business Research, 86, 190-201.

Munoz-Doyangue, M. F., \& Nieto, M. (2012). Individual creativity performance and the quality of interpersonal relationships. Individual Management \& Data Systems, 112(1), 125-145.

Obeidat, A. (2019). IT Adaption with Knowledge Conversion Process (SECI). Management Science Letters, 9(13), 22412252

Obeidat, A. M., \& Otibi, G. A. (2015). The impact of knowledge sharing tools on levels of organizational learning (Field Study on Jordanian Commercial Banks). Australian Journal of Basic and Applied Sciences, 9(5), 253-267.

Obeidat, B.Y, Abdallah, A.B, Aqqad, N.O, Akhoershiedah, AH.Q., \& Maqableh, M. (2017). The effect of intellectual capital on organizational performance: The mediating role of knowledge sharing. Communications and Network, 9, 1-27.

Ofoegbu, O.E. \& Akanbi, P.A. (2012). The influence of strategic agility on the perceived performance of manufacturing firms in Nigeria. International Business \& Economics Research Journal, 11(2), 153-160.

Overby, E., Bharadwaj, A., \&Sambamurthy, V. (2006). Enterprise agility and the enabling role of information technology. European Journal of Information Systems, 15(2), 120-131.

Saffar, N., \& Obeidat, A. (2020). The effect of total quality management practices on employee performance: The moderating role of knowledge sharing. Management Science Letters, 10(1), 77-90.

Sajdak, M. (2015). Compilation of operational and strategic agility for ensuring the highest efficiency of company operations. Economics and Management, 7(2), 20-25.

Santala, M. (2009). Strategic Agility in a small knowledge intensive business service company: Case SWOT Consulting. Master Thesis. Department of Marketing and Management. Helsinki School of Economics: Finland.

Scarbrough, H., Swan, J. \& Preston, J. (1999). Knowledge Management: A Literature Review. London, Institute of Personnel and Development.

Sekaran, U. (2006). Research Methods for business: A skill building approach. New York, NY: John Willy and Sons.

Tallon, P. P., \& Pinsonneault, A. (2011). Competing perspectives on the link between strategic information technology alignment and organizational agility: Insights from a mediation model. MIS Quarterly, 35(2), 463- 486.

Tsai, K.C. (2012). Play, Imagination, and Creativity: A Brief Literature Review. Journal of Education and Learning, 1(2), $15-20$.

Uriarte, J.R., \& Filemon, A. (2008). Introduction to Knowledge Management. ASEAN Foundation: Indonesia.

Vokurka, R. \& Fliedner, G. (1998). The journey toward agility. Industrial Management and Data Systems, 98(4), $165-171$.

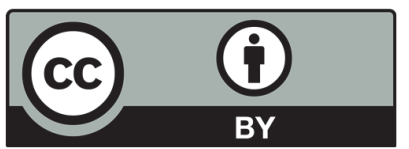

(C) 2020 by the authors; licensee Growing Science, Canada. This is an open access article distributed under the terms and conditions of the Creative Commons Attribution (CC-BY) license (http://creativecommons.org/licenses/by/4.0/). 